\title{
Da literatura negra à literatura afro-feminina
}

\author{
Ana Rita Santiago da Silva \\ Universidade Federal do Recôncavo da Babia (Cachoeira, Brasil)
}

RESUMO: O PRESENTE TEXTO TEM COMO EIXOS TEMÁTICOS: AUTORIA, LITERATURA E IDENTIDADES. DISCUTE-SE POR MEIO DELES OS SIGNOS LITERATURA NEGRA E LITERATURA AFRO-FEMININA. POR ESSES SEGMENTOS LITERÁRIOS, AUTORES/AS NEGROS/AS TECEM VERSOS E NARRATIVAS COM MARCAS DISCURSIVAS EM QUE TRAÇOS DE AFRICANIDADES SÃO EVIDENCIADOS. TEM-SE COMO OBJETIVO COMPREENDER AS TESSITURAS DESSES PROJETOS ESTÉTICOS, QUE COMPÕEM A LITERATURA BRASILEIRA, LEVANDO EM CONSIDERAÇÃO AS TENSÕES, AMBIVALEENCIAS, CONTESTAÇÕES, PERTINÊNCIAS E NEGOCIAÇÕES QUE CIRCUNDAM ESSAS DESIGNAÇÕES.

ABSTRACT: THIS ARTICLE TAKES AUTHORSHIP, LITERATURE, AND IDENTITY AS ITS THEMES, WITH A VIEW TO DISCUSSING THE LABELS AFRO-FEMALE LITERATURE AND BLACK LITERATURE. BY WAY OF THESE LITERARY MARKERS, MALE AND FEMALE BLACK AUTHORS THREAD DISCURSIVE ELEMENTS CHARACTERIZED BY THEIR AFRICAN TRAITS THROUGH THEIR VERSES AND NARRATIVES. I AIM TO ANALYZE THE WEAVE OF THEIR AESTHETIC PROJECTS, WHICH MAKE SIGNAL CONTRIBUTIONS TO BRAZILIAN LITERATURE, BY TAKING INTO ACCOUNT THE TENSIONS, AMBIGUITIES, CHALLENGES, PERTINENCES AND NEGOTIATIONS SURROUNDING THESE TERMS.

PALAVRAS-CHAVE: AUTORIA, LITERATURA, IDENTIDADES, AFRICANIDADES. KEYWORDS: AUTHORSHIP, LITERATURE, IDENTITY, AFRICANNESS. 


\section{lgumas palavras iniciais}

Este texto tem como objetivo trazer à baila provocações, tensões e proposições apontadas pela produção literária - aqui denominada e reconhecida como literatura negra e literatura afro-feminina - de homens e mulheres negras. Esses projetos literários como veremos concretizam-se a partir de olhares críticos e imaginários, considerando as relações étnicorraciais e de gênero como justapostas, a fim de trazer à tona possíveis diálogos, contraditos e contradições existentes entre os sujeitos autores/as e suas criações literárias.

Compreendo literatura negra como um segmento da literatura brasileira, logo como um projeto literário, comprometido com temáticas afins aos legados afrobrasileiros, forjado por escritores/as negros/as que assim se declaram e que assim é denominado por eles/as, por estudiosos/as, leitores/as e críticos/as. Já a literatura afro-feminina é uma produção de autoria de mulheres negras que se constitui por temas femininos e de feminismo negro comprometidos com estratégias políticas civilizatórias e de alteridades, circunscrevendo narrações de negritudes femininas/feminismos por elementos de memórias ancestrais, de tradições e culturas africano-brasileiras, do passado histórico e de experiências vividas, positiva e negativamente, como mulheres negras. Em um movimento de reversão, elas escrevem, como se apresentam neste texto, para (des)silenciarem as suas vozes autorais e para, pela escrita, inventarem novos perfis de mulheres, sem a prevalência do imaginário e das formações discursivas do poder masculino, mas com poder de fala e de decisão, logo senhoras de si mesmas.

\section{A literatura negra em debate: tensões e convergências}

A literatura negra apresenta tessituras, narrativas e versos comprometidos politicamente com histórias e elementos da memória ancestral e de tradições africanas e afro-brasileiras (DUARTE, 2005); caracterizada, segundo Benedita G. Damasceno, ao se referir à poesia negra, por apresentar, entre outros aspectos "[...] a procura e/ou afirmação da identidade negra; [...] o uso de temas da vida e da população negra resultante de vivências próprias ou de estudos e observações conscientes; a reprodução de ritmos negros; [...]" (DAMASCENO, 1988, p. 69). 
Parece oportuno, diante dessas especificidades, enfrentar mais uma discussão sobre esse projeto estético, que compõe variados entendimentos e resiste ainda assim em meio a debates e ambivalências. Embora haja pluralidade de compreensão, há de se certificar de que não são poucas as complexidades, ambiguidades e controvérsias que permeiam e abalam seus sentidos e pertinências nos circuitos literários, acadêmicos e entre os/as escritores que se reconhecem como negros/as.

Expressões como literatura afro-brasileira e literatura negra não são expressões hegemônicas e consensuais, pois não faltam críticos, estudiosos e escritores que as refutam por considerá-las, entre outros motivos, incipientes e inadequadas para a arte literária, que se pretende única e universal, como demonstração da linguagem e arte da palavra, permitindo no máximo a nacionalidade e as circunstâncias geográficas. Ser tão somente literatura brasileira é suficiente para caracterizar os textos artísticos produzidos no Brasil. Tal constatação, por vezes, já garante a sua natureza e neutraliza outras especificidades, tais como raça, etnia e gênero.

Essa é uma das afirmações que sustenta os argumentos daqueles grupos e indivíduos que se opõem à designação literatura negra. Ora, se for possível admitir como legítima a problemática regionalização, tal como literatura mineira, gaúcha, baiana, nordestina, por exemplo, e a delimitação da nacionalidade no âmbito da arte literária, ainda que com controvérsias, também poderão ser oportunas e viáveis outras adjetivações atribuídas à literatura, não menos problemáticas em seu entorno, como indígena, cigana, feminina, negra, afro-feminina etc., como indicadoras de busca de alteridades, de afirmações e de construção de identidades e de diferenças.

Na prática, ao se admitir uma textualidade de escritores/as negros/as, pautada na vivência e tramas de tornar-se negro na sociedade brasileira, implica perfilhar os entraves e dilemas das relações sociais e, acima de tudo, étnicorraciais, estabelecidos pelo racismo. Implica problematizá-los, subjetivamente, forjar agenciamentos de formas e expressões literárias, que acrescentem outras significações ao ser negro (a) no Brasil. Implica ainda entender que, conforme Eduardo A. Duarte, a "[...] conformação teórica da literatura 'negra', 'afro-brasileira' ou 'afro-descendente' passa, necessariamente, pelo abalo da noção de uma identidade nacional una e coesa [...]" (DUARTE, 2005, p. 113). 
No bojo das discussões acerca da literatura negra, posicionamentos como os de Domício Proença Filho merece atenção, visto que oportuniza repensar sobre a composição do segmento da literatura brasileira. Ele avalia como indevida e envolvida por sutilezas a designação literatura negra, por entendê-la como "[...] sério risco de fazer o jogo do preconceito velado" (PROENÇA FILHO, 1988, p. 15). Tal risco é inconveniente e pouco pertinente, na medida em que existe uma tradição de escrita sobre o negro, que se desenha como comprometida com representações de uma supremacia racial branca, mediante a deformação da imagem dos não brancos, aqui, mais especificamente, de negros e de suas negritudes. Em verdade, o jogo do preconceito já está (ex) posto na produção artístico-literária brasileira. Aquilo que o estudioso chama de risco, certamente, se constitui como possibilidade de destecer tessituras nutridas por depreciações presentes nas teias literárias e de tecer textos com fios afirmativos de identidades negras brasileiras.

Para ele, ainda, há outro limite e perigo nesse risco de adjetivação, ao situar "[...] radicalmente uma autovalorização da condição negra por emulação, equivalência ou oposição à condição branca [...], diante até da dificuldade de se estabelecer limites entre uma e outra no miscigenado universo da cultura nacional" (PROENÇA FILHO, 1988, p. 15). Vale ressaltar que a cultura nacional se apresenta pouco coesa e de modo bem controverso, haja vista que ela é pluri/multi e intercultural, formada por um mosaico de culturas. Além disso, se denota um uso carnavalizado, folclorizado e banalizado de traços culturais negros, não só pelas culturas de mídias, mas também por segmentos institucionais, o que dificulta o seu acolhimento e o exercício da alteridade.

Acrescentam-se à compreensão de Proença Filho argumentos de Zilá Bernd, que se posiciona diante desse segmento literário e de sua denominação, literatura negra, pouco confortável com a adjetivação epidérmica e denotativa de aspectos étnicorraciais. Ela reconhece, no entanto, a legitimidade da designação, a partir de duas acepções: no sentido amplo, como aquela " [...] feita por quem quer que seja, desde que reveladora de dimensões específicas da condição do negro ou dos descendentes de negros, enquanto grupo étnico culturalmente singularizado" (BERND, 1988, p. 21). E, no sentido restrito, como uma arte literária “[...] feita por negros ou descendentes assumidos de negros [...] reveladora de visões de mundo, de ideologias e de modos de realizações que, por força de condições atávicas, sociais e históricas, se carac- 
terizam por uma certa especificidade, ligada a um intuito definido de singularidade cultural" (BERND, 1988, p. 21).

A literatura negra, entretanto, não se caracteriza apenas pelos discursos sobre as dimensões específicas da condição do negro e pelas singularidades culturais, mas, acima de tudo, pelo sujeito da enunciação: há explicitamente entre escritores (as) negros (as), que se declaram inseridos na literatura negra, um empenho por inventar representações em que se revertam as que aparecem marcadas por exotismos e inferioridades. Há na literatura negra um eu/nós que se expressa, (auto) representando, por meio de simbologias e repertórios que insinuam deslocamentos de posições de negação e exclusão para vivências de promoção de empoderamentos.

Por conta disso, escritores/as negros/as agenciam na escrita significações sociopolíticas e literárias que propõem outros paradigmas e interesses culturais e intelectuais. Isso, possivelmente, também justifica estudos, publicações, eventos, programas e núcleos, que surgem em ambientes acadêmicos, não acadêmicos e artístico-culturais, permitindo, segundo Miriam Alves (2002), que diferentes singularidades e proposições possam vir à tona na expressão literária.

O poema "Para ouvir e entender 'estrela", de Luis Cuti Silva, bem ilustra as afirmativas em torno da literatura negra, pois apresenta fios poéticos de identidades negras que desafiam práticas culturais hegemônicas que pouco reconhecem as diversidades étnicorraciais e culturais.

\section{Se Papai Noel}

Não trouxer boneca preta

\section{Neste Natal}

Meta-lhe o pé no saco! (SILVA, 1998, p. 51)

Esse pequeno poema de versos curtos tem um tom reivindicatório em prol de visibilidade de um objeto feminino negro - uma boneca preta -. Como exercício de poder, a voz poética sugere uma ação de resistência que não se esgota na força física, mas se estende ao protesto. Pela exigência de uma bo- 
neca preta, possivelmente perpassa o interesse de incluir, em uma dimensão de interculturalidades, figuras negras como repertórios também portadores de saberes e culturas.

A exigência de um brinquedo infantil feminino, no poema, pode sugerir outro paradigma de formação identitária. É preciso, já na infância, a circulação de signos que inibam práticas de assimilação e de branqueamento e promovam o autorreconhecimento imbuído de referências positivadas de africanidades. Talvez por isso enquanto, por um lado, fios identitários, repertórios culturais negros e histórias, forjados em representações e formações discursivas pouco afirmativas, por exemplo, são encenados como inusitados, a fim de que sua exibição seja revestida de espetacularizações, em que as fronteiras entre o real e o imaginário sejam diluídas e sejam visibilizadas de forma entrelaçada. Por outro, produtores/as da literatura negra, como esse poeta, riscam uma escrita diferenciadora desse cenário, elegendo outros fios discursivos, em que sejam realçadas e entrelaçadas dimensões culturais e históricas mais valorativas.

Kátia Bezerra (2002), ao se referir aos autores/as negros/as que, na década de 80 , reivindicam que suas vozes sejam escutadas, afirma que a literatura negra colabora com a construção de formas alternativas de (auto) representações, logo de identidades e com o fim da interdição de vozes negras literárias. A experiência de reversão e de (des) silenciamento significa fomento de práticas de valorização de negritudes ou de desidealização do negro e do branco, como discute Cuti Silva (2002).

Pela literatura negra, autores/as negros/as, pois, podem elaborar dizeres e contraditos e, ao mesmo tempo, recriar seus contextos de enunciação. Neste sentido, é um projeto literário que tem traços distintivos de representações, discursos e narratividades comprometidos com desmobilizações de identidades negras imutáveis e pouco relacionais e de desfigurações de atributos negativos de suas memórias ancestrais e referências culturais.

Escritores/as negros/as não apenas apropriam-se da palavra poética para (des)contar o passado histórico de negros/as. Eles/as ainda utilizam a literatura negra também para provocar a sociedade brasileira quanto às relações étnicorraciais; para afirmar que a lógica do consumo, que sustenta os postulados e negócios da sociedade do espetáculo, define a comercialização de identidades negras, a partir de uma exposição, por vezes, unificadora e estereoti- 
pada, de elementos e vivências culturais homogêneas, fixas e sem dinamismo, inerente aos entrecruzamentos da vida em trânsito.

A literatura negra não só agrega autores/as e obras não instituídas pelo cânone, construídas longe de estereótipos, estigmas e discursos pautados na ideologia do embranquecimento, como também sugere mudanças nas relações inter-raciais, apontando uma nova ordem, como assinala Cuti Silva (2002). Ela provoca a tradição literária brasileira no que se refere ao que se vislumbra como cultura e identidade nacional homogênea e singular, uma vez que permite compreender, no campo imaginário, uma escrita marcada pela diversidade e também por cenas e agendas de formações discursivas sobre o tornar-se negro/a no Brasil.

Apesar dos debates em torno da literatura negra, ela sinaliza uma contraposição efetiva à tradição da literatura, quanto à representação das negritudes, bem como indica uma produção literária, de homens e mulheres negras, que se desenha no Brasil, a qual se constitui em uma manifestação efetiva e densa de um discurso inovador, que, em suas representações, se contrapõe ao já estabelecido. Ela, portanto, indica outras maneiras de inserir na tradição literária formas diferenciadoras de inventar identidades, afastadas de preconceitos e racismos e próximas de autoafirmação, de conquista de autonomia e, concomitantemente, de inter-relação, alteridades e negociação.

Por tal projeto estético, podem-se vislumbrar vozes individuais e coletivas que se enunciam e se constroem - eu/nós - e não se negam negras. Talvez por isso seja necessário, ainda que em meio a algumas ambiguidades e controvérsias, assegurar, sem idealizações, sua validade e reconhecimento, fortalecendo fóruns que possibilitem dar visibilidade às vozes negras literárias, pois, como retrata Duarte, suas produções ainda não estão satisfatoriamente presentes e consolidadas no mercado editorial, permanecendo "[...] intacto o processo de obliteração que deixa no limbo de nossa história a prosa e a poesia de inúmeros autores afro-brasileiros do passado [...]” (DUARTE, 2005, p. 115).

\section{A literatura afro-feminina: dilemas e tessituras}

Não sem menos conflitos que a literatura negra, debates também se acirram em torno da literatura afro-feminina, provocando estudos e pesquisas 
sobre a escrita literária de autoras negras. Diante de tal contexto, este texto também apresenta uma discussão sobre literatura de autoria feminina negra, com ênfase na criação de vozes poéticas e em construções discursivas e imaginárias de femininos, cotejadas com anseios pela escrita e com vozes literárias que vislumbrem emancipação e resistência.

Certamente, a literatura afro-feminina não se configura por tentar sobrepor aquela produzida pelos homens. Tampouco assim se compreende pelo seu estilo, sua forma, nem por ser a expressão de uma possível subjetividade feminina ou até mesmo por ser escrita por mulheres. As temáticas, discursos e representações de personagens femininas e de seus universos são, pois, definidores da escrita literária feminina, a qual é tensionada e nutrida pelo desejo de autonomia política e cultural e de conquistas de espaço público.

Pretende-se com a literatura afro-feminina elaborar discursos em que se possam fiar e ficcionalizar mazelas advindas de práticas racistas e sexistas, mas também, em tom de lirismo, tecer versos e prosas que re-elaborem identidades, entoem e inventem amores, dissabores, dores, histórias, resistências e ancestralidades. Para tanto, escritoras negras, de várias regiões do Brasil, cientes e associadas (ou não) a circuitos de literatura negra ou a outros segmentos, buscam garantir estratégias de escrita, publicações e divulgação de suas produções literárias, a fim de romper com o esquecimento e a não autorização a que, historicamente, estão submetidas suas vozes e autoria.

É nessa perspectiva que se apresenta o poema "Paradoxo", de Mel Adún que, em um território discursivo e imaginário, desmobiliza ditos sobre identidades amparados em anulações e estigmas, riscando escritos que promovem novos lugares e posturas para uma voz feminina. Diferentemente de cantos que subestimam imagens femininas negras, no poema, a graça e o encanto delas são sobrelevados.

Não vou mais lavar os pratos,

Agradeço a Sobral.

Vou ser agora meu bem, viu, meu mal?

Cansei de ser você: de sonhar seus chatos sonhos

Cansei de me emperiquitar

Pra encontros enfadonhos.

Agora serei meu bem, 
Vou reaprender a deitar

E a sonhar sonhos meus

Com minhas cores prediletas.

Sem pensar em sentar de pernas cruzadas

Sem ligar pra depilar

Não quero baile de debutantes,

Tampouco ter filhos ou casar.

Agora vou ser meu bem, viu meu mal?

Vou ser pós-moderna, pelo tempo que quiser

Brilhar como Yaa Asantewaa

Vou voltar a ser mulher.

Quando um dia acordar

E lavar os pratos por vontade

E me emperiquitar por vaidade.

Casar porque me apaixonei

E parir porque eu quis,

Serei para todo o sempre meu bem

Viu meu mal? (ADÚN, 2008, p. 40)

A voz poética decide-se por abolir papéis serviçais, a ela atribuídos, que indiquem negação de si para viver em função de projetos de vida e sonhos de outrem, optando por assumir os rumos de sua vida, querendo-se senhora de suas vontades, paixões e prazer. Sua luta parece ser solitária, pois consiste em voltar a si mesma, colocando-se também no centro das palavras. Em sua busca e conquista de liberdade ecoam, silenciam e ruminam outras vozes poéticas que também decidem mostrar-se e assinar a autoria de seus destinos.

A voz dialoga com a outra de Não vou mais lavar os pratos, de Cristiane Sobral (2000), a quem a autora dedica seus versos. De subalterna e invisibilizada, a voz poética se contorna dons de si e livre para ser, agir e sentir. Ser livre é também uma meta dessa voz, para assim atingir seu empoderamento. Não dá mais para ficar apenas cuidando dos outros e pronta para atender às necessidades alheias, inclusive daqueles que lhe acompanha. Chegou o momento de buscar a realização de seus desejos de libertação do jugo da submissão e de começar a ser, a pensar e a decidir sobre si e, acima de tudo, a querer bem a si mesma. 
Neste sentido, os versos tornam-se um lugar decisivo para mudar os percursos da vida e de escolha, por isso pretende que seja emancipadora ou, pelo menos, transgressora. É uma textualidade que se pretende revolucionária, uma vez que almeja romper com as tramas opressivas e de aprisionamentos do pensamento masculino, já postos pela linguagem, por conseguinte pela comunicação, concepções de mundo e pelas relações de poder.

A literatura afro-feminina, semelhante ao processo histórico de consolidação da literatura negra, se destaca não só com um tom de protesto e de denúncia, mas, sobretudo, por reescrever, cantar e ficcionalizar mundos, dramas, sonhos, experiências pessoais e socioculturais que lembram as memórias literárias de antepassadas/os e recriam novas palavras e escritas femininas negras. É constante, na produção literária de autoria feminina negra, o desenho de vozes e personagens negras sedutoras, não pelos seus aspectos físicos, mas pela sua força, coragem e decisão pela conquista da emancipação feminina negra individual e coletiva. Aparecem, ainda, em seus textos, figuras femininas negras, ávidas pela afirmação de si, ou simplesmente pelo desejo de tornar-se, de estarem cientes de seus dramas, como o racismo, a solidão e o sexismo, ou tão somente pelo sonho de permanecerem no mundo (e em seus mundos) como senhoras de si e de suas vontades.

A literatura afro-feminina, neste ínterim, pode ser considerada como um processo contínuo de (re) invenções de memórias, histórias e narrações sobre identidades, femininos e feminismos negros. Há nela um "retorno" dinâmico ao passado, ou seja, há um reconto de memórias ressignificadas, aliado a cenas de histórias, sonhos, vivências e resistências, no passado e no presente, vislumbrando cenas e agendas que gerem sonhos e conquistas no futuro.

Assim, pelo projeto literário afro-feminino, desenham-se discursos em que vozes literárias negras e femininas, destituídas de submissão, forjam uma escrita em que (re) inventam sentidos, para si e para outros/as, e se cantam repertórios e eventos histórico-culturais negros. A escrita, desse modo, desponta como uma ação transgressora, em que se anulam possíveis significados estigmatizantes e se insinuam outras possibilidades de leituras de significantes, do construir-se mulher, do vivido e do porvir. Por ela, desfilam rastros de significados de identidades negras que migram entre as ressignificações discutidas por Stuart Hall (2000), peculiares à dinamicidade, ao entrecruzamento de culturas e da vida em sociedades e à afirmação de traços culturais relacionados a patrimônios e histórias. 
Como arte da palavra, a literatura afro-feminina valoriza legados intelectuais e culturais africano-brasileiros da tradição, saberes e práticas ancestrais de populações negras e desconstrói discursos poéticos e ficcionais que promovem seu recalque. As possíveis proposições poéticas nos permitem afirmar com Conceição Evaristo: “[...] os textos femininos negros, para além de um sentido estético, buscam semantizar outro movimento, aquele que abriga todas as suas lutas. Torna-se o lugar da escrita, como direito, assim como se torna o lugar da vida” (EVARISTO, 2005, p. 206).

Os sujeitos poéticos e narradores, que compõem a literatura afro-feminina, por esse viés, se apresentam dispostos a buscarem, pela e com a palavra, o direito à voz. Esse exercício de poder pode ser compreendido como um ato de resistência peculiar às relações de poder e não como um subproduto, já que, segundo Foucault, "[...] para resistir, é preciso que a resistência seja como o poder. Tão inventiva, tão móvel, tão produtiva quanto ele. Que, como ele, venha de 'baixo' e se distribua estrategicamente” (FOUCAULT, 2002, p. 241).

\section{Considerações Finais}

Apesar de identificar os latentes limites, a transitoriedade, o desconforto e a incipiência das categorias conceituais literatura negra e literatura afro-feminina, estou convicta de que não são somente etiqueta ou rótulo atribuído a uma manifestação literária. Ao contrário, longe de minimizar e/ou confundir um gênero discursivo com a cor da pele, sexo ou gênero é, em verdade, mais uma oportunidade de trazer à baila a necessidade de coalizões a uma escritura literária que se quer imaginária e, simultaneamente, comprometida com ideais emancipatórios, antipatriarcais e antirracistas.

Da história da literatura negra, elabora-se, paulatinamente, outro projeto literário, que é a literatura afro-feminina, no qual mulheres negras autoras inventam uma escrita de si/nós, em que também aparecem dilemas, realidades e imaginários concernentes aos seus mundos, sonhos, histórias, interesses, desejos e sentimentos. Sua pretensão é colaborar com a rescisão de um passado de representações figuradas pela depreciação de atributos étnicorraciais e de gênero, em um tom denunciativo e de dessilenciamento de vozes literárias negras femininas. 


\section{Referências bibliográficas}

ADÚN, Mel. Paradoxo. In Cadernos negros. poemas afro-brasileiros. Vol. 31. São Paulo: Quilombhoje, 2008, p. 40.

ALVES, Miriam. Cadernos negros (número 1): estado de alerta no fogo cruzado. In FONSECA, Maria Nazareth Soares; FIGUEREDO, Ma do Carmo (Org.). Poéticas afro-brasileiras. Belo Horizonte: Mazza: PUC Minas, 2002.

BERND, Zilá. Introdução à literatura negra. Porto Alegre: Mercado Aberto, 1988.

BEZERRA, Kátia da Costa. A cor da ternura: tecendo os fios da memória. In FONSECA, $\mathrm{M}^{\mathrm{a}}$ Nazareth Soares; FIGUEREDO, $\mathrm{M}^{\mathrm{a}}$ do Carmo (Org.). Poéticas afro-brasileiras. Belo Horizonte: Mazza: PUC Minas, 2002.

DAMASCENO, Benedita Gouveia. Poesia negra no modernismo brasileiro. Campinas: Pontes, 1988.

DUARTE, Eduardo de Assis. Literatura, politica, identidades. Belo Horizonte: FALEUFMG, 2005.

EVARISTO, Conceição. Gênero e etnia: uma escre(vivência) de dupla face. In MOREIRA, Nadilza Martins de Barros; SCHNEIDER, Liane (Orgs.). Mulheres no mundo. Etnia, marginalidade e diáspora. João Pessoa: Ed. Universitária; Ideia, 2005, p. 202-211.

FILHO, Domício Proença. O negro na literatura brasileira. In Boletim bibliográfico Biblioteca Mário de Andrade. São Paulo, Biblioteca Mario de Andrade, v.49, n.14, jan./ dez.1988, p 13-25.

FOUCAULT, Michel. Microfísica do poder. 17 ed. Trad. Roberto Machado. Rio de Janeiro: Grall, 2002.

HALL, Stuart. Quem precisa da identidade? In: SILVA, Tomaz Tadeu da (org); HALL, Stuart; WOODWARD, Kathryn. Identidade e diferença. A perspectiva dos Estudos Culturais. Petrópolis: Vozes, 2000.

SILVA. Luis Cuti. Para ouvir e entender "estrela". In Cadernos negros - Os melhores poemas. São Paulo: Quilombhoje, 1998, p. 51.

, Luiz Cuti. O leitor e o texto afro-brasileiro. In FONSECA, $\mathrm{M}^{\mathrm{a}}$ Nazareth Soares; FIGUEREDO, $\mathrm{M}^{\mathrm{a}}$ do Carmo (Orgs.). Poéticas afro-brasileiras. Belo Horizonte: Mazza: PUC Minas, 2002.

SOBRAL, Cristiane. Não vou mais lavar os pratos. In Cadernos negros. Poemas Afrobrasileiros. São Paulo: Quilombhoje, n. 23, 2000.

Recebido em 10 de agosto e aprovado em 30 de setembro de 2010. 